\title{
FEMALE EFL LEARNERS' REQUEST REALIZATION IN RELATION TO THEIR ETHNIC BACKGROUNDS
}

\author{
Artanti Puspita Sari \\ (artanti_psari@yahoo.com) \\ Universitas Tridinanti, Indonesia
}

\begin{abstract}
The choice of strategies and modifications of speech acts in conversational communication may be correlated with sociolinguistic factors, such as ethnicity, social distance and dominance. Requests, as a part of speech acts, provide an interesting focus in this research because requests are face threatening acts. This article was based on a research conducted in the period of April to June 2008. The subjects of the research were female EFL learners of English Education Study Program at Sriwijaya University Inderalaya in South Sumatera Indonesia. The investigation utilized a combination of qualitative and quantitative methods, revealed that: (1) in terms of patterns, the female EFL learners of different ethnic groups performed similar request patterns, (2) in terms of correlation, the subjects' ethnic backgrounds did not correlate with their strategies, yet, their ethnic backgrounds had correlation with the subjects' request modifications, (3) the subjects' request strategies and modifications did not correlate with social distance and dominance. The information gained can be utilized as a basis for integrating cultures and social dimensions between speakers and hearers into the teaching of EFL as well as EIL to increase students' intercultural and pragmatic competence.
\end{abstract}

Key words: requests, strategies, modifications, ethnic backgrounds

In conversational communication, when a speaker produces an utterance, the sounds produced are meaningful. The utterance conveys the speaker's intended message to the communication counterpart. In return, the counterpart responds to the utterance on the basis of the speaker's inferred message. In speaking, a speaker performs particular kinds of actions which express intentions, such as directing, stating, promising, etc. Requests, which are part of the Directive Speech Acts, provide an interesting focus in this 
research because requests are face threatening acts. According to Brown and Levinson (1987:60-61), face threatening means that when a speaker makes a request, the act may threaten the counterpart's face- the public self-image that every member of a society wants to claim in order to maintain self-esteem. Requests are sensitive to social distance and dominance between the participants. The more distant the relationship between the participants and the more dominance the hearer, the more polite the act of request used. A student who requests a teacher to repeat an explanation about a certain subject at school might say, 'Would you please explain about the material one more time, Sir?'. To a classmate in the same situation the student might simply say, 'Can you repeat that?' when requesting for a certain explanation to be repeated.

Another factor that influences the way people speak is ethnic background or ethnicity (Holmes, 2001:175). Hassall (2001) revealed that Danish learners of English and German overuse please and, its equivalent in German, bitte on requests and are claimed to favor these modifiers because the modifiers explicitly mark the utterance as being a request. These learners tended to choose explicit and transparent means of expression rather than the ambiguous ones. A research done by Blum-Kulka, et.al. (1989: 149) on the requests of five ethnic groups showed that Argentinian Spanish speakers were found to be most direct, followed by Israelis speakers of Hebrew. Australian English speakers were the least direct. The native speakers of German and Canadian were at the mid-point in the research continuum of directness.

This study was conducted based on the prediction that variation in request acts and modifications might also exist within the different ethnic groups of EFL learners at the English Study Program Sriwijaya University, Inderalaya, South Sumatera. The number of EFL learners majoring in the Study Program was 174 students comprising of 149 females and 25 males with different ethnic backgrounds. Before the study was conducted, in March 2008, the writer assessed the students' ethnic backgrounds. There were 124 students of semester 2, 4, 6 and 8 filling out a set of questionnaires. Among the 124 respondents, 106 were females and only 18 were males. They came from more than 24 ethnics. The most dominant ones were Java, Palembang and Komering. Many students also come from mixed ethnicities, that is, more than one ethnic group.

A research by Syahri (2007) on request realizations of 68 EFL learners from the same study program proved that, in terms of directness and indirectness, the subjects utilized conventionally indirect strategies most frequently, direct strategies as the second and non-conventionally indirect 
strategies as the least frequent. He suggested that the role of local dialects, which is one of the characteristics of ethnic background on request realizations, is open to further investigation. Based on Holmes' (2001:150-182) statements, it can be expected that EFL learners of different ethnic background choose different patterns of request strategies and modifications.

\section{METHOD}

Both qualitative and quantitative methods were applied in this study. According to Creswell (1994), it is possible to use a combination of qualitative and quantitative findings. In this type of research, one method can be used to elaborate, enhance or illustrate the results from the other method. The qualitative method was concerned with in-depth analysis of request strategies and modifications performed by the subjects in accordance with request strategies in Cross-cultural Speech Act Realization Project (CCSARP) and request modifications put forward by Blum-Kulka et. al. (1989). Analysis of the assemblage of social dimensions (social distance and dominance was also conducted. The in-depth analysis was done to have the explanatory adequacy about request strategies made by students of different ethnicity. The quantitative method was considered as subsidiary to the qualitative method. It was applied for identifying the categories and frequencies of request strategies and determining whether or not the strategies used by the subjects had correlations with their ethnicity.

To limit the number of samples and to gain a deep analysis, the subjects were chosen purposively based on their ethnic backgrounds. Only those from the eight major ethnic categories were selected. Using these criteria, the number of students who were taken as samples was forty nine participants. The data of this study were collected by means of betweenmethod triangulation technique, i.e. combining quantitative data by using questionnaires in the form of DCT (Discourse Completion Test), qualitative data procedures through observations by means of role-plays, and interviews.

Each subject was given a DCT to fill out, responding to the written tasks. After the data from the DCT is obtained, subjects whose answers were ambiguous were interviewed for confirming the responses that they made. For the role play, the participants were selected randomly from each ethnic and linguistic organizational competence category so each has at

least one representative for the role play. In the role-plays, a number of twenty seven female students took part. Each successfully acted out six scenarios which summed up to 162 dialogues. 


\section{Questionnaires}

The questionnaires given to the subjects were in the forms of Discourse Completion Tests (DCT). The DCT questionnaire were ready made ones which had been used in a research on request acts by Syahri (2007) on a sample of 68 Sriwijaya University undergraduate students. The subjects were elicited to give respond to the task written in the questionnaires by writing their acts of requesting in the blank spaces provided. Blum-kulka, et. al. (1989) points out that DCT was originally developed for comparing the speech act realization of native and nonnative speakers of Hebrew). Syahri (2007) explains that the DCT used for this research consists of a number of situations followed by spaces in which the subjects were asked to provide the linguistic form of request acts as though they are in real-life interactions. The DCT deals with social distance and social power (dominance). Social distance (SD) is indicated by familiarity. +SD means that the speaker $(\mathrm{S})$ is not familiar with the hearer $(\mathrm{H})$ and $-\mathrm{SD}$ means that $\mathrm{S}$ is familiar with $\mathrm{H}$. Dominance (D) is indicated by social power. $+\mathrm{D}$ indicates that either the $\mathrm{S}$ is higher in dominance $(\mathrm{S}>\mathrm{H})$ or lower $(\mathrm{S}<\mathrm{H})$. $-\mathrm{D}$ indicates that the participants are of equal status.

\section{Observation}

In order to have more productive data that reflect the subjects' competence in enacting the requesting acts, observation was conducted in this study. The observation was conducted in a classroom. The subjects were given a set of tasks containing scenarios of role plays in which they know what to do after reading the tasks. The scenarios contain situations in which they are asked to stimulate in the role plays. The tasks in the scenarios were given to pairs of subjects and the researcher observed how each pair stimulates the role plays. Productive data and records of all relevant data to the act of requesting were observed deliberately. The scenarios of the role play used for this research are ready made ones. The role play scenarios have been used in a research on request acts by Syahri (2007) on a sample of 68 Sriwijaya University undergraduate students. Similar to the DCT, the situations in the role plays also represent variations on the dimensions of social distance (familiarity) and dominance (social power). 


\section{Interview}

In order to be valid, the data gathered by means of questionnaires and observations were cross-checked by means of interview. Some subjects were interviewed to confirm the strategies that they use in requesting in cases where the clarity of their responds to the questionnaires is ambiguous or when there are differences between their responds to the questionnaires and their request performance in the role plays. These were conducted to prevent some potential biases that may occur when responding to questionnaires and practicing in the role plays. Because most of the responses were clear enough, only few interviews were carried out.

\section{FINDINGS AND DISCUSSION}

In this article, the discussion will be focused on the following findings: (1) the strategies and modifications female EFL learners of different ethnic backgrounds, (2) the correlation between the female EFL learners' ethnic backgrounds with their request strategies and modifications, (3) how social distance and dominance assemble in the female EFL learners' request strategies and modifications.

\section{Request Strategies and Modifications}

\section{Strategies}

When speakers realize requests, they also perform the request by means of strategies. In order to analyze strategies of speech acts, including requests, a tool has been provided by Blum-Kulka, et. al. (1989:18). The Cross-cultural Speech Act Realization Project (CCSARP) found by BlumKulka et. al. (1989) classifies speech act strategies into three categories: (1) direct strategies, (2) conventionally indirect strategies, and (3) nonconventionally indirect strategies. The direct strategies are divided into 4 strategies: (1) mood derivable, (2) explicit performatives, (3) hedged performatives, (4) obligation statements, (4) want or need statements. The conventionally indirect strategies includes: (1) suggestory formulae and (2) query preparatory. The last category, non-conventionally indirect strategies are strong and mild hints. The following sentences are some examples of request strategies applied by the subjects of this research.

Direct Strategies

1. Mood derivable 
(1) Please turn down the music.

(2) Please correct the wrong one.

2. Hedged Performatives

(1) I want to ask your permission to have final exams on the other day.

(2) I want to ask your permission whether I may follow your course or not.

3. Want Statements

(1) I really hope you can rearrange another day for me.

(2) I hope you can help me for this.

Conventionally Indirect Strategies

Query Preparatory

1. Would you like to turn down the music, please?

2. Would you like to lend me a pen?

Non-conventionally Indirect Strategies

Strong Hints

1. Excuse me. I really like this T-shirt. Is there a suitable size for me?

2. Which one of these is suitable size for me?

The data show that the subjects utilized direct, conventionally indirect and non-conventionally indirect strategies in the realization of their requests. However within each group of ethnicity, the conventionally indirect strategies in the form query preparatory were most frequently used. The conventionally indirect strategies in the form of query preparatory made a percentage of $92 \%$ of the responses. Table 1 illustrates that the distribution of strategies within the ethnic groups were similar.

Table 1. Distribution of Strategies in the DCT

\begin{tabular}{lcccccccccc}
\hline \multirow{2}{*}{$\begin{array}{l}\text { Ethnic back- } \\
\text { ground }\end{array}$} & \multicolumn{9}{c}{ DS } & \multicolumn{7}{c}{ CIrategies } & \multirow{2}{*}{ Total } \\
\cline { 2 - 9 } & MD & EP & HP & OS & WS & SF & QP & SH & MH & \\
\hline Batakese & 4 & 0 & 0 & 0 & 0 & 0 & 39 & 1 & 0 & 44 \\
\% & $\mathbf{9 \%}$ & - & - & - & - & - & $\mathbf{9 0 \%}$ & $\mathbf{2 \%}$ & - & \\
Javanese & 7 & 0 & 0 & 0 & 0 & 0 & 171 & 2 & 0 & 179 \\
\% & $\mathbf{4 \%}$ & - & - & - & - & - & $\mathbf{9 5 \%}$ & $\mathbf{1 \%}$ & - & \\
Komeringese & 0 & 0 & 1 & 0 & 1 & 0 & 70 & 3 & 0 & 75
\end{tabular}




\begin{tabular}{|c|c|c|c|c|c|c|c|c|c|c|}
\hline$\%$ & - & - & $1 \%$ & - & $1 \%$ & - & $93 \%$ & $4 \%$ & - & \\
\hline Oganese & 1 & 0 & 0 & 0 & 2 & 0 & 42 & 0 & 0 & 45 \\
\hline$\%$ & $2 \%$ & - & - & - & $4 \%$ & - & $93 \%$ & - & - & \\
\hline Palembangese & 6 & 0 & 1 & 0 & 1 & 0 & 66 & 1 & 0 & 75 \\
\hline$\%$ & $8 \%$ & - & $1 \%$ & - & $1 \%$ & - & $88 \%$ & $1 \%$ & - & \\
\hline Mixed SS & 6 & 0 & 0 & 0 & 7 & 0 & 150 & 1 & 0 & 164 \\
\hline$\%$ & $4 \%$ & - & - & - & $4 \%$ & - & $91 \%$ & $1 \%$ & - & \\
\hline Mixed Ind & 4 & 0 & 1 & 0 & 5 & 0 & 138 & 0 & 0 & 148 \\
\hline$\%$ & $3 \%$ & - & $1 \%$ & - & $3 \%$ & - & $93 \%$ & - & - & \\
\hline Total & 28 & 0 & 3 & 0 & 16 & 0 & 675 & 8 & 0 & 730 \\
\hline$\%$ & $4 \%$ & 0\% & $0.4 \%$ & $0 \%$ & $2 \%$ & $0 \%$ & $92 \%$ & $1 \%$ & $0 \%$ & $100 \%$ \\
\hline
\end{tabular}

Notes: $\mathrm{MD}=$ mood derivable

PR = explicit performatives

$\mathrm{SF}=$ suggestory formulae

HP = hedged performatives

$\mathrm{QP}=$ query preparatory

OS = obligatory statements

$\mathrm{SH}=$ strong hint

WS = want statements

$\mathrm{MH}=$ mild hint

The data of the role-plays showed similar result to those of the request strategies in the DCT. As presented in Tabel 2, conventionally indirect strategies outnumbered the other strategies. From the 162 requests made, a total of 131 strategies $(81 \%)$ were conventionally indirect strategies which comprise of $2(1 \%)$ suggestory formulae and $129(80 \%)$ query preparatory. Within each ethnic group, the Batakese group performed 15 conventionally indirect strategies $(83 \%)$ which were all in the form of query preparatory out of 18 requests. The Javanese, Komeringese, Oganese, Palembangese groups, Mixed SS and Mixed Ind realized a percentage of 75\%, 75\%, 73\%, $75 \%, 83 \%$ and $100 \%$ respectively.

Table 2. Distribution of Strategies in the Role-plays

\begin{tabular}{|c|c|c|c|c|c|c|c|c|c|c|}
\hline \multirow{3}{*}{$\begin{array}{l}\text { Ethnic back- } \\
\text { ground }\end{array}$} & \multicolumn{9}{|c|}{ Strategies } & \multirow{3}{*}{ Total } \\
\hline & \multicolumn{5}{|c|}{ DS } & \multicolumn{2}{|c|}{ CIS } & \multicolumn{2}{|c|}{ NIS } & \\
\hline & MD & EP & HP & OS & WS & SF & QP & SH & MH & \\
\hline Batakese & 0 & 0 & 0 & 0 & 0 & 0 & 15 & 3 & 0 & 18 \\
\hline$\%$ & - & - & - & - & - & - & $83 \%$ & $2 \%$ & - & \\
\hline Javanese & 2 & 1 & 0 & 0 & 4 & 1 & 35 & 5 & 0 & 48 \\
\hline$\%$ & $4 \%$ & $2 \%$ & - & - & $8 \%$ & $2 \%$ & $73 \%$ & $1 \%$ & - & \\
\hline Komeringese & 0 & 0 & 1 & 0 & 2 & 0 & 9 & 0 & 0 & 12 \\
\hline$\%$ & - & - & $8 \%$ & - & $2 \%$ & - & $75 \%$ & - & - & \\
\hline Oganese & 1 & 0 & 0 & 0 & 3 & 1 & 13 & 0 & 0 & 18 \\
\hline
\end{tabular}




\begin{tabular}{|c|c|c|c|c|c|c|c|c|c|c|c|}
\hline \multicolumn{12}{|c|}{ Table Continued } \\
\hline \multirow{3}{*}{\multicolumn{2}{|c|}{$\begin{array}{l}\text { Palembang- } \\
\text { nese }\end{array}$}} & $1 \%$ & - & - & - & $2 \%$ & $1 \%$ & $72 \%$ & - & - & \\
\hline & & 0 & 0 & 0 & 0 & 1 & 0 & 9 & 2 & 0 & 12 \\
\hline & & - & - & - & - & $1 \%$ & - & $75 \%$ & $2 \%$ & - & \\
\hline \multirow{2}{*}{\multicolumn{2}{|c|}{ Mixed SS }} & 0 & 0 & 0 & 0 & 4 & 0 & 30 & 2 & 0 & 36 \\
\hline & & - & - & - & - & $1 \%$ & - & $83 \%$ & $1 \%$ & - & \\
\hline \multirow{2}{*}{\multicolumn{2}{|c|}{ Mixed Ind }} & 0 & 0 & 0 & 0 & 0 & 0 & 18 & 0 & 0 & 18 \\
\hline & & - & - & - & - & - & - & $100 \%$ & - & - & \\
\hline \multicolumn{2}{|l|}{ Total } & 3 & 1 & 1 & 0 & 14 & 2 & 129 & 12 & 0 & 162 \\
\hline \multicolumn{2}{|l|}{$\%$} & $2 \%$ & $\begin{array}{c}0.6 \\
\% \\
\end{array}$ & $\begin{array}{c}0.6 \\
\% \\
\end{array}$ & $0 \%$ & $9 \%$ & $1 \%$ & $80 \%$ & $7 \%$ & $0 \%$ & $100 \%$ \\
\hline Notes: & $\begin{array}{l}\mathrm{MD}= \\
\mathrm{PR}= \\
\mathrm{HP}= \\
\mathrm{OS}= \\
\mathrm{WS}=\end{array}$ & $\begin{array}{l}\text { ood d } \\
\text { plicit } \\
\text { dged } \\
\text { ligato } \\
\text { int sta }\end{array}$ & $\begin{array}{l}\text { ivab } \\
\text { erfor } \\
\text { erfor } \\
\text { stat }\end{array}$ & $\begin{array}{l}\text { tives } \\
\text { tives } \\
\text { hents }\end{array}$ & & $\begin{array}{l}\mathrm{SF}= \\
\mathrm{QP}= \\
\mathrm{SH}= \\
\mathrm{MH}=\end{array}$ & $\begin{array}{l}\text { ugges } \\
\text { juery } \\
\text { trong } \\
\text { mild h }\end{array}$ & $\begin{array}{l}\text { ry form } \\
\text { eparato } \\
\text { int } \\
\text { tt }\end{array}$ & & & \\
\hline
\end{tabular}

\section{Modifications}

In request strategies, sometimes speakers modify their requests. BlumKulka, et.al. (1989:273-289) classify strategy modifications into two categories: (1) internal modifications and (2) external modifications. The internal modifications deal with the mitigation and aggravation of the imposition of the hearers which are only dependent on the head acts of the requests, i.e. the utterances containing the acts of requesting. The external modifications are referred to as "supporting moves", or other utterances which existed before or after the head acts. The supportive moves affected the context in which they were embedded, and thus indirectly modified the illocutionary force of the request.

The following data are some examples of internal modifications found in the subjects' responses.

\section{a. Syntactic Upgraders}

1. Interrogatives

(1) Could you please turn down the music?

(2) Can you help us to take the photograph?

2. Negation

(1) If you don't mind to share the textbook with me?

3. Embedded "if" clause

(1) I really appreciate if you turn down the music. 


\section{b. Lexical Upgraders}

1. Consultative device

(1) Is it okay if I borrow your notes?

(2) Do you mind if I take this course?

2. Downtoner

(1) I want to ask your permission whether I may follow your course or not.

3. Politeness device

(1) Please turn down the music.

(2) Would you share your book with me, please?

\section{c. Down Graders}

\section{Intensifier}

\section{(1) It's too loud}

A percentage of $62 \%$ of the whole modifications were in the form of internal modifications. The internal modifications utilized by the subjects of different groups of ethnics and linguistic competence were similar. Most of the groups used interrogative as their device of syntactic internal modifications. For lexical internal modifications they preferred consultative and politeness devices, such as "please" (see Table 3). Although negations, "if" clauses, downtoners and intensifiers were used as well (especially in the intermediate group), the frequency of those devices is not significant (close to $0 \%$ ). This phenomenon is shown by the percentage of each of the said device.

Table 3. Distribution of Internal Request Modifications

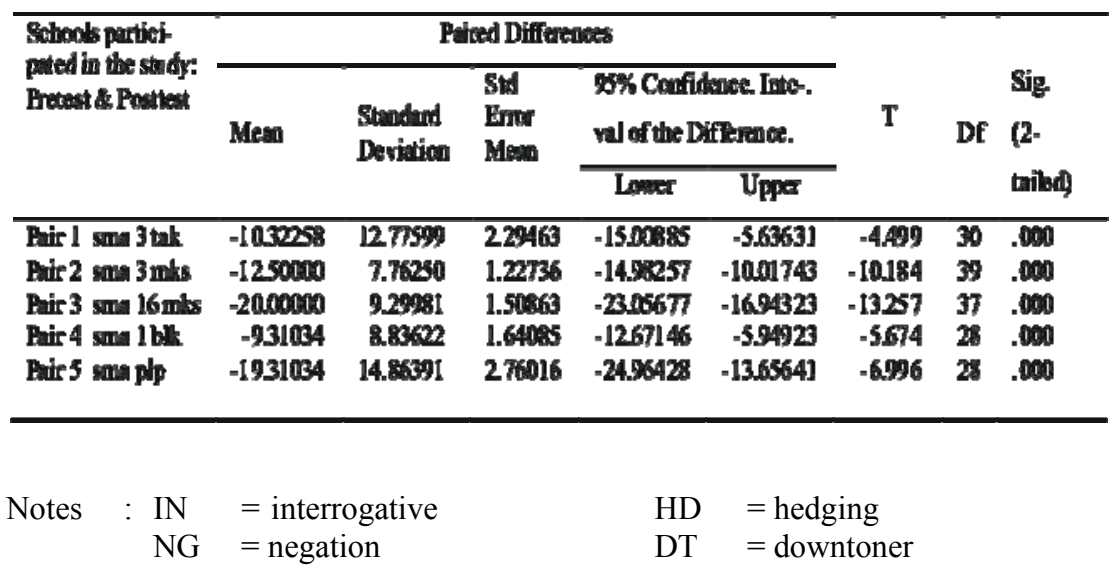




$\begin{array}{lll}\mathrm{PT} & =\text { past tense } & \mathrm{PD}=\text { politeness device } \\ \mathrm{IF} & =\text { embedded "if" clause } & \mathrm{INT}=\text { intensifier } \\ \mathrm{CD} & =\text { consultative device } & \mathrm{EXP}=\text { expletives } \\ \mathrm{UN}=\text { understater } & \mathrm{IM}=\text { internal modifications }\end{array}$

The other $38 \%$ of the modifications were in the form of external modifications. The following data are external modifications found in the subjects responses.

\section{a. Checking on Availability}

(1) Have you any time?

(2) Do you have a pen?

b. Getting precommitment

(1) Would you help me, please?

(2) Can you help me?

(3) Could you help me?

c. Grounder

(1) Can you help me. This lesson is too difficult for me. You seem more understand than me. Please teach me.

(2) I'm sorry, Mam. I'm not sure I can finish it on the due day. So may you extend the deadline?

d. Disarmer

(1) I'm sorry, friend. Actually I don't want to disturb you with your activity, but tomorrow I have a mid-term examination. I am preparing for it this night. So, could you please turn down your tape?

(2) Excuse me, Sir. May I take final exam on another day because the day is my brother's wedding. I know it is not your business, but please I really hope you to can rearrange another day for me.

e. Cost minimizer

(1) Excuse me, Madam. Would you mind to extend the deadline of final paper. I haven't already yet. I have tried. But I promise to finish it as soon as possible.

(2) Excuse me, Sir. I'm your student from the second semester. I didn't come into class in the last meting because I was sick, so I haven't got the handout. May I borrow it from you, Sir? I'll return it as soon as possible.

\section{f. Sweetener}

(1) Excuse me, Sir. Actually I really like your class. So would you mind giving me permission to sit in? 
(2) Hi... I don't really understand the materials of this class and we have to prepare for final exam. I see you understand them much better than me. So, would you help me in getting ready for the exam.

Table 4 illustrates the patterns of external modifications. The most commonly used external modification device is the grounder. Other devices used were checking on availability (2\%), getting a precommitment $(1 \%)$, disarmer $(1 \%)$, cost minimizer $(1 \%)$ and sweetener $(3 \%)$. The three respondents from the Batakese group did not make use of disarmer, cost minimizer and sweetener. It is in line with the common knowledge that they are relatively more direct than most ethnic groups in Indonesia. On the contrary the Oganese group, in which three samples were involved, used the said strategies more frequently than any of the other ethnic groups. In terms of linguistic organizational competence, the external modification patterns of the different groups were also similar.

Table 4. Distribution of External Request Modifications

\begin{tabular}{|c|c|c|c|c|c|c|c|}
\hline \multirow[b]{2}{*}{$\begin{array}{l}\text { Ethnic Back- } \\
\text { ground }\end{array}$} & \multicolumn{7}{|c|}{ External Modifications } \\
\hline & AV & $\mathrm{PC}$ & GR & DA & $\mathrm{CM}$ & SW & $\begin{array}{l}\text { Total of External } \\
\text { Modifications }\end{array}$ \\
\hline Bataknese & 2 & 4 & 26 & 0 & 0 & 0 & 32 \\
\hline Javanese & 10 & 0 & 93 & 3 & 4 & 8 & 118 \\
\hline Komeringese & 6 & 1 & 39 & 2 & 3 & 6 & 57 \\
\hline Oganese & 1 & 2 & 25 & 6 & 4 & 5 & 43 \\
\hline Palembangese & 0 & 2 & 49 & 0 & 1 & 2 & 54 \\
\hline Mixed SS & 6 & 8 & 106 & 0 & 2 & 9 & 131 \\
\hline Mixed Ind & 1 & 1 & 91 & 0 & 3 & 14 & 110 \\
\hline Total & 26 & 18 & 429 & 11 & 17 & 44 & 545 \\
\hline $\operatorname{Avrg}(\Sigma / n)$ & 0.5 & 0.4 & 8.8 & 0.2 & 0.3 & 0.9 & 11,1 \\
\hline$\%$ & $2 \%$ & $1 \%$ & $30 \%$ & $1 \%$ & $1 \%$ & $3 \%$ & $38 \%$ \\
\hline $\mathrm{AV}$ & \multicolumn{7}{|c|}{$=$ checking on availability } \\
\hline $\mathrm{PC}$ & \multicolumn{7}{|c|}{$=$ getting pre commitment } \\
\hline GR & \multicolumn{7}{|c|}{$=$ grounder } \\
\hline $\mathrm{DA}$ & \multicolumn{7}{|c|}{$=$ disarmer } \\
\hline $\mathrm{CM}$ & \multicolumn{7}{|c|}{$=$ cost minimizer } \\
\hline SW & \multicolumn{7}{|c|}{$=$ sweetener } \\
\hline EM & \multicolumn{7}{|c|}{$=$ external modifications } \\
\hline
\end{tabular}




\section{CORRELATIONS}

The application of statistical analysis was utilized to find out whether or not ethnic background correlates with the subjects' choice of request strategies and modifications. Cross tabulations (crosstabs) with chi-square analysis was utilized to find out whether the subjects' request strategies and modifications were related to their ethnic backgrounds. According to Santoso (2005), crosstabs are used to analyze the relationship between variables in rows and in columns, such as interdependence and strength of relation. The statistical analysis was conducted using Statistical Product and Service Solutions (SPSS) software.

Correlation Analysis of Ethnic Background and Request Strategies

From cross tabulation analysis, it can be concluded that:

a. $\mathrm{X}^{2}$ cal $(15.815)<\mathrm{X}^{2}$ table $(21.026)$

b. Probability $(0.2)>\alpha(0.05)$

According to Santoso (2005), if the $\mathrm{X}^{2}$ calculation is less than the $\mathrm{X}^{2}$ table or if the probability (assymp. sig.) is greater than $\alpha$, the rows and columns do not have any relationship. In other words the strategies do not have any correlation with ethnic background.

Correlation Analysis of Ethnic Background and Request Modifications

Table 5 shows that the probability $(0.000)$ is less than $5 \%$ obtained by DCT. It means that there is a significant correlation between ethnic background and request modifications.

Table 5. Analysis of the Correlation between Ethnic Backgrounds and Request Modifications

Chi-square Tests

\begin{tabular}{lccc}
\hline & Value & Df & Asymp. Sig. (2-sided) \\
\hline Pearson Chi-Square & $105.000(\mathrm{a})$ & 42 & .000 \\
Likelihood Ratio & 94.429 & 42 & .000 \\
Linear-by-Linear As- & 3.782 & 1 & .052 \\
sociation & 1431 & & \\
N of Valid Cases & & \\
\hline
\end{tabular}

36 cells $(64,3 \%)$ have expected count less than 5 . The minimum expected count is 0.12 . 


\section{INVOLVEMENT OF SOCIAL DIMENSIONS}

\section{How Social dimensions Assemble in Request Strategies}

As stated previously, the DCT and role-play scenarios were assembled by social dimensions, namely social distance and dominance. Social distance (SD) is indicated by familiarity. + SD means that the speaker (S) is not familiar with the hearer $(\mathrm{H})$ and -SD means that $\mathrm{S}$ is familiar with $\mathrm{H}$. Dominance (D) is indicated by social power. $+\mathrm{D}$ indicates that either the $\mathrm{S}$ is higher in dominance $(\mathrm{S}>\mathrm{H})$ or lower $(\mathrm{S}<\mathrm{H})$. $-\mathrm{D}$ indicates that the participants are of equal status. Four patterns were utilized in the research: 1) SD \& -D, 2)+SD \& -D, 3)-SD \& +D, and 4) +SD \& +D.

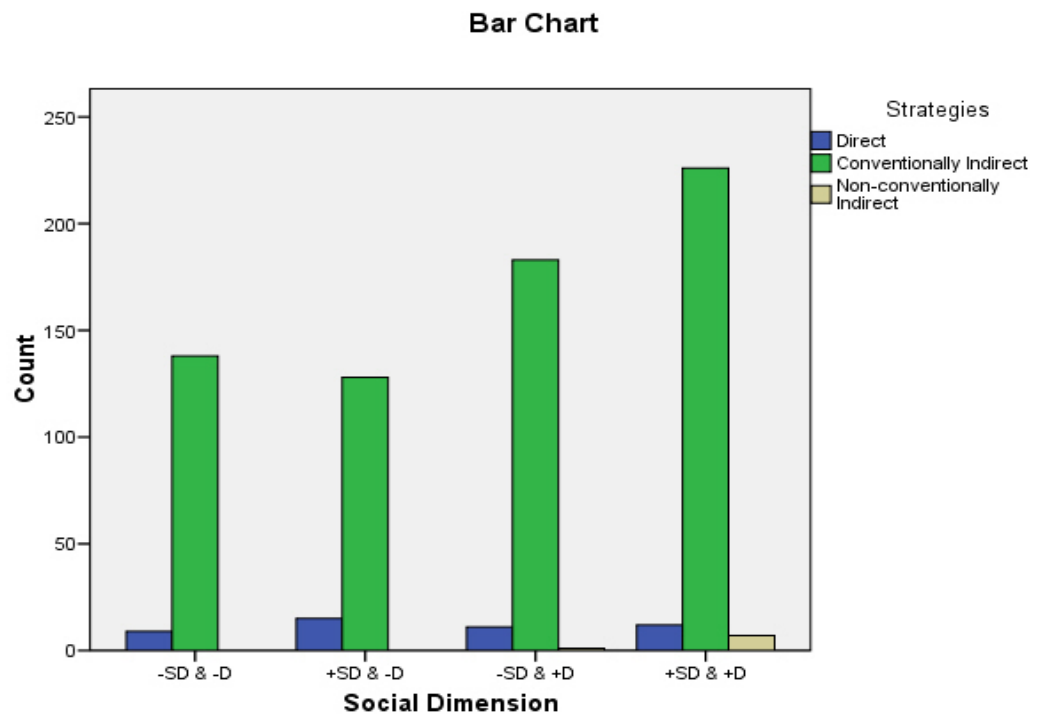

Figure 1. The patterns of Social Dimensions Involvement in Request Strategies

Regardless of relationship patterns, the most frequent strategies across all four patterns were conventionally indirect strategies (see Figure 1). Direct strategies were the second most preferred strategies and nonconventionally indirect strategies were the least preferred. However, there was a tendency that when dominance existed as in pattern 3 and 4 , some subjects felt the need to improvise their requests with one of the non- 
conventionally indirect form of strategies, strong hints. Therefore, some subjects tended to utilize strong hints more frequently. On the contrary, in situations where dominance applied, some subjects utilized mood derivable strategies less frequently.

\section{How Social Dimensions Assemble in Request Modifications}

The distribution of modifications in each group was similar. To summarize the findings, across the different patterns interrogative was the most frequently applied internal modifications in the subjects' request, while

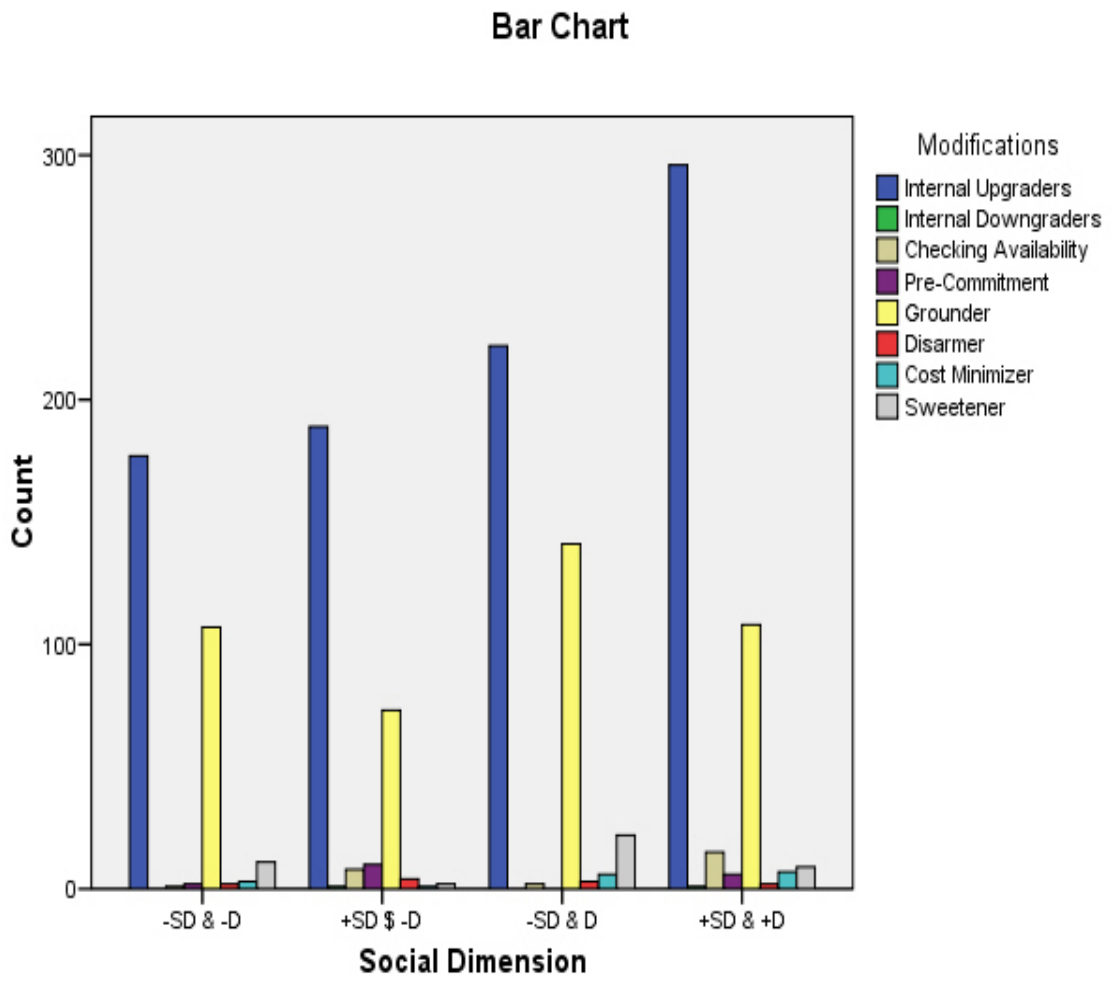

Figure 2. The patterns of Social Dimensions Involvement in Request Modifications 
Grounder was the most preferred form of external modifications. The crosstab statistical analysis showed that the probability $(0.888)$ was greater than $5 \%$. In all of the types of analysis concerning variable dependence, social dimension can be used to predict modifications and vice versa. Nevertheless, the correlation values are close to 0 . It means that the correlations are weak. Although in some cases social dimensions correlated with the subjects' choice of modifications, most of the modification preferences did not have correlation with social dimensions. The patterns of social dimension involvement are given in Figure 2.

\section{CONCLUSIONS AND SUGGESTIONS}

From the study, it can be concluded that EFL learners of different ethnic backgrounds applied similar patterns of request strategies. Social dimensions did not strongly correlate with request strategies. Although, some of their acts of requesting were related to social distance and dominance between the participants, most of the subjects applied similar strategies. The subjects in this research performed a percentage of $92 \%$ of conventionally indirect strategies. This is due to the fact that the subjects were taught to make requests mostly by means of modals which represent one of the characteristics of the conventionally indirect strategies. Therefore, there is a possibility that they lack sensitivity toward social dimension and dominance in using English. Furthermore, although they came from different ethnic backgrounds, the subjects lived in the same environment which allows them to share similar culture.

In relation to modifications, the subjects' ethnic backgrounds do have correlation with their request modifications. The research shows that some ethnic groups did not apply certain types of modification, while others tend to use those modifications more frequently. Respondents from the Batak group did not make use of disarmer, cost minimizer and sweetener. It is in line with the common knowledge that they are relatively more direct than most ethnic groups in Indonesia. On the contrary, the Ogan group, used the said strategies more frequently than any of the other ethnic groups. In terms of social dimensions and dominance, the subjects were not influenced by the pattern of speaker-hearer relationship. They performed similar requests regardless of the type of social dimensions and dominance existing between the speaker and the hearer.

In relation to the findings of this study, some suggestions are addressed to EFL teachers or lecturers. Firstly, pragmatic competence such as the teaching of speech acts should be taught in EFL classrooms so that 
learners' pragmatic competence can develop simultaneously along with their linguistic competence. Secondly, in developing students' pragmatic competence, teachers/lecturers should also incorporate social dimensions and dominance. Thirdly, they should be able to assess learners' pragmatic competence, for example, by making use of DCT and role-plays in their teaching. Small researches in the classroom are also necessary to recognize learners' ability to use English appropriately.

Besides the above mentioned suggestions, it is also worth mentioning that with the growing number of users of English and the use of English as an international language, cultures of different ethnics can also be included in the teaching of English to increase intercultural awareness. The knowledge of many cultures provides insight for EFL learners in understanding discourse of English speakers who come from ethnics other than their own.

\section{REFERENCES}

Blum-Kulka, S., J. House, \& Kasper .G. 1989. Cross-Cultural Pragmatics: Requests and Apologies. Norwood, NJ: Ablex Publishing Corporation.

Brown, P.\& Levinson .S.C. 1987. Politeness: Some Universals in Language Usage. Cambridge: Cambridge University Press.

Cresswell, J.W. 1994. Research Design. Qualitative and Quantitative Approaches. Thousand Oaks: Sage Publications.

Hassall, T. 2001. Modifying Requests in a Second Language. International Review of Applied Linguistics in Language Teaching, 39(4): 259-283.

Holmes, J. 2001. An Introduction to Sociolinguistics (2 ${ }^{\text {nd }}$ Edition). New York: Pearson Education Limited.

Santoso, S. 2005. Menguasai Statistik di Era Informasi dengan SPSS 12. Jakarta:PT. Elex Media Komputindo.

Syahri, I. 2007. Acts of Request as Realized by EFL Learners. Unpublished Dissertation. Malang: State University of Malang.

Syahri, I. 2007. IL Pragmatics: A Methodological Proposal. A paper presented in a seminar held by graduate students of Sriwijaya University. 